\title{
Underdiagnosis of asthma: is the doctor or the patient to blame? The DIMCA project
}

\author{
C P van Schayck, F M M A van der Heijden, G van den Boom, P R S Tirimanna, \\ C L A van Herwaarden
}

\begin{abstract}
Background-It is important to diagnose asthma at an early stage as early treatment may improve the prognosis in the long term. However, many patients do not present at an early stage of the condition so the physician may have difficulty with the diagnosis. A study was therefore undertaken to compare the proportion of patients who underpresented their respiratory symptoms with the proportion of underdiagnosed cases of asthma by the general practitioner (GP). A secondary aim was to investigate whether bad perception of dyspnoea by the patient was a determining factor in the underpresentation of asthma symptoms to the GP.
\end{abstract}

Methods-A random sample of 1155 adult subjects from the general population in the eastern part of the Netherlands was screened for respiratory symptoms and lung function and the results were compared with the numbers of asthma related consultations registered in the medical files of the GP. In subjects with reduced lung function the ability to perceive dyspnoea was investigated during a histamine provocation test in subjects who did and did not report their symptoms to their GP.

Results-Of the random sample of $\mathbf{1 1 5 5}$ subjects $86(7 \%)$ had objective airflow obstruction (forced expiratory volume in one second $\left(F E V_{1}\right)$ below the reference value corrected for age, length, and sex minus 1.64SD on two occasions) and had symptoms suggestive of asthma. Of these 86 subjects only $29(34 \%)$ consulted the GP, which indicates underpresentation by $66 \%$ of patients. Of all subjects with objective airflow obstruction who presented to their GP with respiratory symptoms, $23(79 \%)$ were recorded in the medical files as having asthma, indicating underdiagnosis by the GP in $21 \%$ of cases. Of the subjects with objective airflow obstruction who visited the GP with respiratory symptoms $6 \%$ had bad perception of dyspnoea compared with $26 \%$ of those who did not present to the GP in spite of airflow obstruction $\left(\chi^{2}=3.02, p=0.08\right)$.

Conclusions-Underpresentation to GPs of respiratory symptoms by asthmatic patients contributes significantly to the problem of underdiagnosis of asthma. Underdiagnosis by the GP seems to play a smaller role. Furthermore, there are indications that underpresentation of symp- toms by the patient is at least partly explained by a worse perception of dyspnoea.

(Thorax 2000;55:562-565)

Keywords: asthma; underdiagnosis; underpresentation; general practice

There is still an increase in the morbidity and mortality of asthma ${ }^{12}$ which seems to apply to patients diagnosed as having asthma as well as to those in whom a diagnosis of asthma has not yet been made. ${ }^{3}$ Underdiagnosis and consequent undertreatment might be important in the increased morbidity and mortality of asthma. ${ }^{45}$ Early detection and treatment of asthma might improve the long term prognosis of these patients ${ }^{6}$ and this secondary prevention may also prevent irreversible loss of function. ${ }^{7}$ It is not clear whether the physician or the patient is to blame: is underdiagnosis of asthma caused by the physician who does not adequately interpret the symptoms presented to him (or her) or is it caused by the patient who does not present his or her symptoms to the physician ${ }^{8}$ In the latter case it is not clear why a patient does not present his or her symptoms to the GP. Is this caused by poor perception of the symptom of dyspnoea in particular? ${ }^{9-11}$

The primary aim of this study was to compare the numbers of cases of underpresentation of respiratory symptoms by the patient with underdiagnosis by the GP. A secondary aim was to investigate whether the perception of dyspnoea by patients plays a part in the possible underpresentation of symptoms of asthma to the GP.

\section{Methods}

STUDY DESIGN

This study is part of a larger study, the DIMCA project (early Detection, Intervention and Monitoring of Asthma and COPD) carried out by the Department of General Practice and Social Medicine of the University of Nijmegen. ${ }^{312}$ The project has been ongoing since 1991 and its aim is the early detection, monitoring and, if necessary, early treatment of patients with asthma and chronic obstructive pulmonary disease (COPD). ${ }^{3}$

PATIENTS

A random sample of 1155 subjects aged 25-70 was selected from 10 urban and rural general practices in the eastern part of the Netherlands. In the Netherlands all subjects in the general population are registered in the files of 
Table 1 Patient characteristics

\begin{tabular}{lll}
\hline Variable & $\begin{array}{l}\text { Participants }^{*} \\
(n=1155)\end{array}$ & $\begin{array}{l}\text { Refusalst } \\
(n=34)\end{array}$ \\
\hline${\text { Mean (SD) } \mathrm{FEV}_{1} \text { (\% predicted) }}$ & $96.4(14.6)$ & $96.1(17.5)$ \\
FEV $_{1}$ reversibility (\%) $\ddagger$ & $3.3(4.1)$ & - \\
Sex (\% female) & 55.3 & 61.8 \\
Mean (SD) age (years) & $43.2(11.8)$ & $45.2(13.4)$ \\
Childhood eczema (\%) & 11.4 & 6.1 \\
Current smokers (\%) & 37 & 39 \\
Ever smokers (\%) & 70 & 71 \\
\hline
\end{tabular}

$\mathrm{FEV}_{1}=$ forced expiratory volume in one second.

${ }^{\star}$ Subjects $(\mathrm{n}=1155)$ who participated in the study. Initially 1988 were sampled, 239 were excluded (known asthma or COPD, congestive heart failure, lung diseases other than asthma or COPD, life expectancy less than 11 years) and 594 refused or did not respond.

†Random sample of subjects (34 of 594) who refused to participate at first but eventually agreed to be screened at home.

$\ddagger$ Reversibility in $\mathrm{FEV}_{1}$ at 15 minutes after inhalation of $800 \mu \mathrm{g}$ salbutamol; not assessed in subjects screened at home (as this was an important reason for refusing to participate).

TPercentage of affirmative answers to questionnaire question: "Did you ever experience eczema in childhood?"

a GP. There was no recruitment bias during the selection procedure (described in detail elsewhere, ${ }^{3}{ }^{13}$ see also table 1 ). These 1155 subjects went through an extensive screening programme which included several measurements of forced expiratory volume in one second $\left(\mathrm{FEV}_{1}\right)$ and a comprehensive questionnaire ${ }^{31213}$ which included a question on whether they had ever presented with respiratory problems such as wheezing, coughing, or dyspnoea to the GP. Special attention was paid to the number of subjects with objective airway obstruction and symptoms suggestive of asthma (wheezing, recurrent coughing, or dyspnoea) to investigate further underpresentation and underdiagnosis in this group of higher risk subjects. $\mathrm{FEV}_{1}$ was measured twice in a four month period under standard conditions. ${ }^{14}$ When the $\mathrm{FEV}_{1}$ was less than the reference value (based on age, height, and sex minus 1.64SD) on both occasions it was considered to deviate objectively from normal. ${ }^{14}$

The medical files at the surgeries of the GPs were analysed for asthma related consultations. All files were checked if either asthma related complaints and symptoms, or prescribed asthma drugs, or both, were present. All asthma related consultations were scored. Consultations in which an infection of the upper airways or pharyngitis had been diagnosed were not counted as asthma related consultations. The analysis was limited to five years before the screening date. While the analysis of the GP files only included the last five years, the question whether the patient had ever presented with symptoms covered a much longer period. To validate the method used, one quarter of the subjects were chosen at random and were further checked by analysing the complete patient history from birth (as far as the complete file was available) for the presence of

Table 2 Subjects with objective airflow obstruction and symptoms suggestive of asthma selected from the general population $(n=86)$ : underpresentation by patients and underdiagnosis by general practitioners (GPs)

\begin{tabular}{lll}
\hline & Yes & No \\
\hline Presented symptoms to GP & $29(34 \%)$ & $57(66 \%)$ \\
Asthma related consultation in file at GP surgery & $23(79 \%)$ & $6(21 \%)$ \\
\hline
\end{tabular}

asthma related consultations. In no case had a diagnostic misclassification been made.

PERCEPTION OF DYSPNOEA

For the second question of the study a random sample of subjects with objective lung function was selected as above. Of the 86 subjects with reduced lung function, 47 were further investigated to determine their ability to perceive dyspnoea by assessing the change in Borg score during a histamine provocation test carried out using the method described by Brand et al. ${ }^{9}$ The $\mathrm{PC}_{20}$ histamine was determined in a lung function laboratory in subjects with a baseline $\mathrm{FEV}_{1}$ of more than one litre and more than $50 \%$ of the reference value. After saline solution histamine was administered at five minute intervals in doses ranging from 0.03 to $32 \mathrm{mg} / \mathrm{ml}$ and the subjects were asked to report their dyspnoea 30 seconds after inhalation, immediately preceding measurement of the $\mathrm{FEV}_{1}$. The inhalation was stopped when the baseline $\mathrm{FEV}_{1}$ had decreased by $20 \%$ or when a dose of $32 \mathrm{mg} / \mathrm{ml}$ had been reached. The degree of dyspnoea was scored on the Borg scale, a 12 point ordinal scale ranging from 0 (no dyspnoea) and 0.5 (very, very slight dyspnoea) to 10 (maximally dyspnoea). ${ }^{9}$ The $\mathrm{FEV}_{1}$ was measured and recorded in readings accurate to $10 \mathrm{ml}$. The slightest decrease or increase therefore corresponded with a change in $\mathrm{FEV}_{1}$ of at least $10 \mathrm{ml}$. After the measurements the subjects were classified into two groups: "good perceivers" in whom a decrease in $\mathrm{FEV}_{1}$ was accompanied by an increase in the Borg score and "poor perceivers" in whom there was a $20 \%$ decrease in $\mathrm{FEV}_{1}$ or an observed decrease in $\mathrm{FEV}_{1}$ after the last doubling dose of $32 \mathrm{mg} / \mathrm{ml}$ histamine which was not accompanied by any increase in the Borg score. ${ }^{9}$ It was then determined whether or not patients in the two groups with reduced lung function had consulted the GP with asthma related symptoms.

\section{Results}

Of the random sample of 1155 subjects, 86 had objective airflow obstruction as well as symptoms suggestive of asthma. The number of subjects with asthma related consultations in the GP files and the number who had consulted the GP with symptoms suggestive of asthma are shown in table 2 . Of the 86 subjects only 29 (34\%) had ever presented their symptoms to the GP; thus, $66 \%$ of the subjects had not consulted their GP even though they had objective airflow obstruction. Of the 29 subjects who had consulted their GP, however, six $(21 \%)$ were not diagnosed as having asthma by the GP.

Forty seven subjects from the general population sample with decreased $\mathrm{FEV}_{1}$ were investigated as to their ability to perceive dyspnoea by means of a histamine provocation test and Borg score measurements (table 3). Of the 16 subjects who had presented to the GP, 15 $(94 \%)$ were "good perceivers" and one $(6 \%)$ was categorised as a "poor perceiver". Of the 31 subjects who had not presented to the GP, $23(74 \%)$ were categorised as "good perceiv- 
Table 3 A random sample of 47 subjects with obstructive airflow obstruction selected from the general population: relation between presentation of symptoms to the general practitioner (GP) and the perception of dyspnoea

\begin{tabular}{llll}
\hline \multicolumn{4}{c}{ Perception } \\
\cline { 2 - 4 } & Poor & Good & Total \\
\hline Presented symptoms to GP & & \\
Yes & $1(6 \%)$ & $15(94 \%)$ & $16(34 \%)$ \\
No & $8(26 \%)$ & $23(74 \%)$ & $31(66 \%)$ \\
Total & $9(19 \%)$ & $38(81 \%)$ & $47(100 \%)$ \\
\hline
\end{tabular}

ers" and eight (26\%) as "poor perceivers". Although the difference was more than fourfold, it was not statistically significant $\left(\chi^{2}=\right.$ $3.02, \mathrm{p}=0.08)$. However, if an $\mathrm{FEV}_{1}$ value of $\leqslant 70 \%$ or $60 \%$ of the reference value is used as a more strict limit for an objective pulmonary disorder, the tendency is clearer, with no subjects who presented with symptoms to the GP being a "poor perceiver" of dyspnoea compared with $19 \%$ and $33 \%$, respectively, of patients with an $\mathrm{FEV}_{1}$ of $\leqslant 70 \%$ or $60 \%$ on two occasions who did not present to their GP with symptoms in spite of having an objective pulmonary abnormality.

\section{Discussion}

The question of the extent to which the presentation of symptoms by the patient to the GP is picked up and translated into a diagnosis is preceded by another question-namely, if the patient presents the symptoms to the GP. From the results of this study it appears that most patients (66\%) do not present bronchial symptoms to the GP, even though they have decreased lung function, so they remain unknown to the GP. However, patients who do present with respiratory problems and who have reduced lung function are not always recognised as such. In this group the interpretation of the complaint at presentation (mainly cough) has probably been a wrong one. In looking for possible causes of underdiagnosis of asthma, this study has indicated that the problem is mainly due to the patient and only partly to the GP. It is also important to note that only a minority of the subjects with objective lung abnormalities $(23 / 86,27 \%)$ could be diagnosed by the GP as asthmatic. It has been pointed out that underdiagnosis of asthma is a significant problem, not only in adults but also in children. ${ }^{15-19}$ Further study of methods of more active screening or case finding of asthma in high risk groups in general practice is therefore justified, as has been previously suggested. ${ }^{15}$

In this paper the presence of asthma was based on airflow obstruction together with symptoms of wheezing, recurrent coughing, or dyspnoea. This is a pragmatic diagnosis and not a "gold standard" based on an official definition according to the international guidelines (such as the presence of reversibility of obstruction or bronchial hyperresponsiveness). It is therefore possible that not all 86 subjects had asthma and some might have had COPD.

There is considerable evidence that dyspnoea has a pronounced effect on quality of life. We therefore assumed that dyspnoea is likely to be the symptom which is most likely to cause patients to consult their GP. This paper therefore does not focus on the perception of asthma but, rather, is limited to the perception of dyspnoea. The objective parameter most related to dyspnoea is the reduction in $\mathrm{FEV}_{1}$.

We have investigated whether the ability to perceive airway obstruction determines whether or not a patient visits his or her GP with concomitant airway symptoms (dyspnoea). It should be pointed out that the time at which the question concerning the presentation of symptoms was answered and the time at which the perception of dyspnoea was measured were not synchronous, and this may have confounded the results. Another problem is that the presence of airway obstruction does not always result in the presence of bronchial symptoms. ${ }^{20}$ There are even indications that patients with more severe asthma have a reduced perception of dyspnoea. ${ }^{21}$

This study has shown that the perception of dyspnoea seems to determine, at least in part, the presentation to the GP with symptoms. Of the subjects with bronchial obstruction who did visit the GP with airway symptoms, $6 \%$ had a poor perception of dyspnoea while, of the subjects who did not visit the GP in spite of bronchial obstruction, the percentage with a poor perception of dyspnoea was more than four times higher at $26 \%$. Because of the small number of patients studied, these figures are not significant but, when subjects with more severe airway obstruction were considered, the tendency was clearly confirmed. It could be argued that, because a poor perception of dyspnoea is probably a cause of underpresentation by the patients, neither the physician nor the patient is to blame for the underdiagnosis of asthma in the general population.

One limitation of this study was the relatively small number of subjects with reduced lung function in the general population with only 86 of 1155 subjects having clear reduced lung function.

One of the factors in determining the role of perception of airway obstruction in the underpresentation of respiratory symptoms is the ability to influence this perception positively. If perception plays a large part in the presentation of symptoms, its improvement might logically result in better presentation of symptoms which could contribute to an early diagnosis of asthma. ${ }^{22}$ It is important to know the level at which perception could possibly be influenced. If the process of perceiving takes place at the cellular level, a positive influence on the ability to perceive is attributed to corticosteroids. Roisman et $a l^{23}$ claim that perception by asthmatic subjects is related to the presence of eosinophilic inflammatory cells and epithelial damage in the airways. They conclude that corticosteroids are associated with improvement in the perception of bradykinin induced bronchoconstriction, a mediator produced endogenously in asthma. However, this would not be helpful for subjects who are not yet diagnosed and who therefore would not be treated with steroids. In case of a more psychological or behavioural foundation to percep- 
tion, a better solution might be better education of possible patients to promote reporting of symptoms to GPs.

In summary, underpresentation of respiratory symptoms by asthmatic patients plays probably the most important role in the underdiagnosis of this disease. Furthermore, there are indications that underpresentation of symptoms by patients is caused by a decreased perception of dyspnoea. Future research should focus on possible methods of improving the perception and awareness of patients with symptoms of asthma.

1 Ayres JG, Noah ND, Fleming DM. Incidence of episodes of acute asthma and acute bronchitis in general practice 1976-87. Br f Gen Pract 1993;43:361-4. 2 Lange P, Ulrik CS, Vestbo J, for the Copenhagen City Heart
Study Group. Mortality in adults with self reported asthma. Lancet 1996;347:1285-9.

3 van den Boom G, van Schayck CP, Rutten-van Mölken MPMH, et al. Active detection of COPD and asthma in the general population: results and economic consequences of the DIMCA programme. Am $\mathcal{F}$ Respir Crit Care Med 1998; 158:1730-8.

4 Speight AN, Lee DA, Hey EN. Underdiagnosis and undertreatment of asthma in childhood. BMf 1983;286:1253-6.

5 Barnes PJ. Blunted perception and death from asthma. $N$ Engl f Med 1994;30:1383-4.

6 Dompeling E, van Schayck CP, van Grunsven PM, et al. Slowing the deterioration of asthma and COPD observed during bronchodilator therapy by adding inhaled corticosteroids. A 4-year randomized controlled study with salbutamol and ipratropium bromide. Ann Intern Med 1993;118:770-8.

7 Haahtela T, Järvinen M, Kava T, et al. Effects of reducing or discontinuing inhaled budesonide in patients with mild asthma. N Engl F Med 1994;331:700-5.

8 Levy M. Delay in diagnosing asthma. Is the nature of general practice to blame? f R Coll Gen Pract 1986;36:52-

9 Brand PLP, Rijcken B, Schouten JP, et al. Perception of airways obstruction in a random population sample: relation- ship to airways hyperresponsiveness in the absence of respiratory symptoms. Am Rev Respir Dis 1992;146:396401 .

10 Kendrick AH, Hoggs CMB, Whitfield MJ, et al. Accuracy of perception of severity of asthma patients treated in general practice. BMF 1993;307:422-4.

11 Barnes PJ. Poorly perceived asthma. Thorax 1992;47:408-9.

12 van Grunsven PM, van Schayck CP, van Kollenburg HJM, et al. The role of "fear of corticosteroids" in nonparticipation in early intervention with inhaled corticosteroids in asthma and COPD in general practice. Eur Respir $f$ asthma and COPD

13 Tirimanna PRS, van Schayck CP, den Otter JJ, et al. Prevalence of asthma and COPD in general practice since 1992; has it changed since 1977? Br f Gen Pract 1996;46:277-81.

14 Quanjer PH, Tammeling GJ, Cotes JE. Lung volumes and forced ventilatory flows. Report of Working Party on Standardization of Lung Function Tests, European Community for Steel and Coal. Official Statement of the European Respiratory Society. Eur Respir f Suppl 1993;16:5-40.

15 Neville RG, Bryce FP, Robertson FM, et al. Diagnosis and treatment of asthma in children: usefulness of a review of medical records. Br F Gen Pract 1992;42:5001-3.

16 Bryce FP, Neville RG, Crombie IK, et al. Controlled trial of an audit facilitator in diagnosis and treatment of childhood asthma in general practice. BMF 1995;310:838-42.

17 Heeijne Den Bak J. Prevalence and management of asthma in children under 16 in one practice. BMF 1986;292:175-

18 Toop LJ, Howie JGR, Paxton FM. Night cough and general practice research. F R Coll Gen Pract 1986;36:76-7.

19 Levy M, Bell L. General practice audit of asthma in childhood. BMf 1984;289:1115-6.

20 Schayck CP van, Folgering H, Otter JJ den, et al. Does the continuous use of bronchodilators mask the progression of asthma or chronic bronchitis? Fam Pract 1992; 9:397-404.

21 Bijl-Hofland ID, Cloosterman SG, Folgering H, et al. Relation of the perception of airway obstruction to the severity of asthma. Thorax 1999;54:15-9.

22 Bijl-Hofland ID, Cloosterman SG, Folgering H, et al. Measuring breathlessness during histamine challenge: a simple standardized procedure in asthmatic patients. Eur Respir $\mathcal{F}$ 1999;13:955-60.

23 Roisman GL. Peiffer C, Lacronique JG, et al. Perception of bronchial obstruction in asthmatic patients: relationship with bronchial eosinophilic inflammation and epithelial damage and effect of corticosteroid treatment. $\mathcal{F}$ Clin Invest 1995;96:12-21. 